\title{
Epidemiologia dos acidentes por animais peçonhentos em duas regiões do estado de Minas Gerais, no período de 2007 a 2012
}

\author{
Carla Graziela Paes Ladeira, Janice Lima Silveira, Claudio Machado
}

\begin{abstract}
Resumo
Acidentes envolvendo animais peçonhentos fazem parte das chamadas doenças negligenciadas, enquadram-se entre os agravos brasileiros de notificação compulsória e recebem, das políticas de saúde, enfoque direcionado à provisão de soro antiveneno. As estratégias de atenção a esses agravos propõem a articulação da produção e distribuição dos antivenenos com a qualificação de recursos humanos e o monitoramento dos acidentes pela vigilância epidemiológica, objetivando capacitar profissionais para realização de atendimento adequado, administração correta do soro e produção precisa das notificações, além de prover, às localidades, tipologia e quantidade de antiveneno apropriadas aos respectivos perfis e distribuições dos acidentes. Observam-se, no entanto, dificuldades na aplicação dessas estratégias, com a reduzida disponibilidade de disciplinas formativas em graduações nas áreas biológicas e da saúde; com a insuficiente oferta de capacitações sobre o tema e, sobretudo, com a produção inadequada de notificações. Nos formulários de notificação são descritas informações pessoais do paciente e as relativas ao agravo, a sintomatologia, o diagnóstico alcançado, a gravidade, o tratamento proposto e a evolução do caso. Omissões ou incompatibilidades podem, portanto, ser verificadas a partir dos dados registrados, sugerindo erros e incongruências em diagnósticos ou em prescrições terapêuticas e evidenciando inadequações na oferta de soro às localidades, uma vez que as instâncias governamentais utilizam informações contidas nesses registros para quantificar e especificar a provisão. Este trabalho visa verificar as notificações dos acidentes com animais peçonhentos em duas regiões do estado de Minas Gerais, compreendendo os perfis e as distribuições epidemiológicas e a situação das notificações. Foram obtidos, junto ao Sistema de Informação de Agravos de Notificação (SINAN), dados dos acidentes ocorridos, entre 2007 e 2012, nas áreas da Superintendência de Saúde de Ponte Nova, na região da Zona da Mata, e das microrregiões de Itajubá, Santa Rita do Sapucaí, Pouso Alegre e São Lourenço, na região do Sul de Minas. Em ambas as regiões, indivíduos do sexo masculino e pessoas entre 20 e 59 anos foram majoritariamente acometidas. Prevaleceram acidentes classificados como leve e a maior parcela evoluiu para cura. A concentração de agravos foi maior durante o verão. Na região da Zona da Mata, foram notificados 3.137 acidentes, correspondendo a 92 casos para cada dez mil habitantes. Escorpiões estiveram envolvidos no maior número de envenenamentos (70\%) e os agravos ignorados/branco representaram 2,6\%. Gravidade e evolução ignoradas/branco totalizaram, respectivamente, 4,6 e 7,5\%. Na região do Sul de Minas, foram notificados 2.196 acidentes, sendo a maioria causada por aranhas $(36 \%)$ e perfazendo 25 casos por dez mil habitantes. A categoria ignorados/branco representou $11 \%$ do total de acidentes. O perfil e a distribuição da epidemiologia de acidentes por animais peçonhentos contribuem na orientação de políticas e ações de prevenção, atenção e tratamento desses agravos nas regiões da Zona da Mata e do Sul de Minas. A incompletude dos dados, evidenciada na expressividade da categoria ignorado/branco, por sua vez, reforça a necessidade de informação e capacitação profissional sobre a temática e suscita a continuidade das investigações no sentido de reconhecer e propor reparações às incongruências nas notificações.
\end{abstract}

Descritores: Animais peçonhentos; Epidemiologia; SINAN 